\title{
A Comparative Study of Energy Consumption for Residential HVAC Systems Using EnergyPlus
}

\author{
Samah K. Alghoul \\ Department of Mechanical and Industrial Engineering, University of Tripoli, Tripoli, Libya \\ Email address: \\ s.alghoul@uot.edu.ly \\ To cite this article: \\ Samah K. Alghoul. A Comparative Study of Energy Consumption for Residential HVAC Systems Using EnergyPlus. Humanities and Social \\ Sciences. Vol. 2, No. 2, 2017, pp. 98-103. doi: 10.11648/j.ajmie.20170202.16
}

Received: November 2, 2016; Accepted: January 24, 2017; Published: January 24, 2017

\begin{abstract}
Energy conservation and sustainability have become an attractive field for research due to the growth in population and continuing search for better living standards. Heating, Ventilation, and Air Conditioning (HVAC) systems account for almost half of consumed energy in buildings and around 10 to $20 \%$ of total energy consumption in developed countries. In general, the trend of installing central HVAC systems increases in residential and commercial buildings. In this research, a study of energy consumption of HVAC systems in residential buildings has been conducted with the aim to compare those systems from an energy consumption point of view. The final goal of this research is to reduce energy requirements of residential buildings sector to save energy and reduce carbon emission. A medium size residential building in the city of Tripoli, Libya, was selected as a case study. EnergyPlus building simulation software along with OpenStudio software were used to model the house and HVAC systems. The results show that the virtual component "ideal air loads" used in EnergyPlus is very easy to use, however, its calculated energy consumption is overestimated compared to other models. Therefore, using that component can be misleading and may result in high monthly and annually energy consumption results. The results also show that in a residential building, unitary systems consume the least annual energy consumption compared to other models. It was concluded that variations in energy consumption of the considered HVAC systems decrease as the coefficient of performance (COP) increases and visa verse.
\end{abstract}

Keywords: Residential Buildings, Energy Consumption, HVAC Systems, Coefficient of Performance, EnergyPlus

\section{Introduction}

One-third of the world's energy consumption is associated with Buildings [1]. Air conditioning systems consume more energy than any other devices used in building services, that was estimated to be about half of the energy consumed in buildings, and between $10 \%$ to $20 \%$ of total energy consumed in developed countries [2]. In Libya, the consumed energy used to cool and heat residential buildings is about $18 \%$ of the domestic energy consumption and about $6 \%$ of the total energy [3] as shown in Figure 1. Hence, reduction in energy requirements by HVAC systems in buildings may lead to an improvement in building energy saving and efficiency.

A significant amount of research has been conducted recently in reviewing different HVAC systems, their energy consumption, and methods used in modeling and simulating those systems. Reviews and comparisons of modeling methods for HVAC systems have got a considerable attention [4-8]. Vakiloroaya et al. [9] focused on various strategies used in saving energy required for operating HVAC systems and they carried out a comparative study between different approaches that improve the performance of HVAC systems. Albayyaa et al. [10] compared energy consumption for Air Conditioning systems among various residential buildings. Their results show that modern buildings require 53\% less energy compared to old buildings. Zhou et al. [11, 12] compared HVAC models in three building energy modeling programs (BEMPs). The conclusion of their work is that although the software is capable of modeling conventional HVAC systems, however, there were discrepancies in the results due to differences in input parameters and control strategies. They also found that EnergyPlus has more comprehensive component models than the other programs. Hasan et al. [13] used combined simulation and optimization for the minimization of life cycle cost of a 
detached house. They used the IDA ICE 3.0 simulation program and the GenOpt 2.0 optimization program to optimize five selected design variables in the building construction and HVAC system.

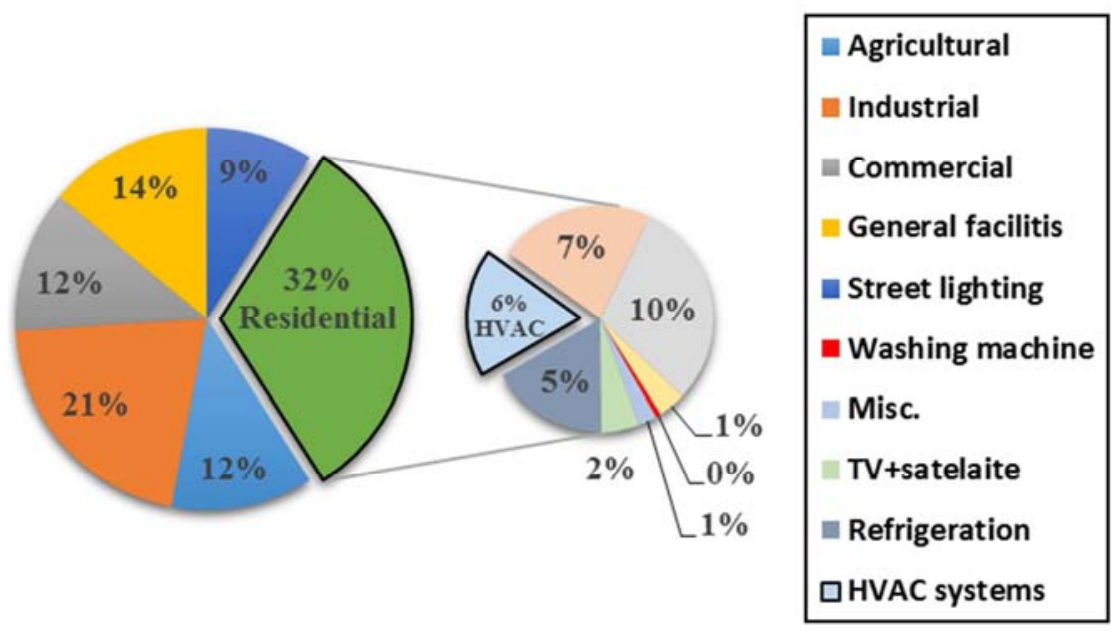

Figure 1. Percentages of electric energy consumed in Libya in 2012 [3].

Many types of research have been conducted using EnergyPlus software, a building simulation software that is created and updated by the USA Department of Energy [14]. The application of this software is numerous, for example, Shabunko et al. [15, 16] used EnergyPlus for benchmarking while Alghoul et al. [17] used EnergyPlus to study energy consumption and energy saving through different types of double glazed windows. Fumo et al. [18] used EnergyPlus for energy consumption calculations in order to develop a simple methodology for energy consumption. It is important to mention that using EnergyPlus in energy-related research has been expanding and cannot be fully presented in this paper.

The effect of HVAC systems on the environment is significant in mainly two ways. Firstly, refrigerants create a greenhouse effect that leads to a global warming. Secondly, carbon dioxide generated from the energy used to power HVAC systems also leads to a greenhouse effect. Therefore, reducing energy requirements and size of HVAC systems might result in reducing the global warming.

The main goal of this study is to compare HVAC systems by using EnergyPlus software from energy point of view. Those HVAC systems are: Ideal air loads (a virtual component is used in EnergyPlus software), Variable Flow Refrigerant, Packaged Rooftop Heat Pump, Packaged Terminal Heat Pump, and Unitary systems. The study also aims to reduce energy consumption in residential buildings due to HVAC systems and to analyze the influence of related parameters.

\section{Methodology}

In this work energy consumption of HVAC systems in residential buildings has been studied. The building is located in the city of Tripoli, Libya which is described in details in next section.

EnergyPlus simulation software/engine with SketchUp and
OpenStudio software were used to calculate the required cooling and heating capacity and the energy consumption of the whole building. SketchUp was used to draw and create the model geometry, while OpenStudio is used to modify model properties namely: constructions, materials, occupancy, internal loads, and schedules [19]. Then, EnergyPlus is used to perform an annual energy simulation $[20,21]$ in order to estimate building's annual energy consumption. Finally, obtained results are presented in OpenStudio in SI units.

EnergyPlus carries out a zone heat balance for the load calculations. Zone heat balance calculations are divided into surface and air components. TARP and DOE-2 algorithms were selected for inside and outside surface convection, respectively, and Conduction Transfer Function (CTF) solution algorithm was chosen for the calculations of the conduction through walls [20]. EnergyPlus calculates heating and cooling loads required to maintain the zone at preset setpoints conditions and therefore calculates annual energy requirements of HVAC systems and for the entire building.

The Ideal air loads component along with four HVAC systems namely: Variable Refrigerant Flow (VRF), Packaged Rooftop Heat Pump (PRHP), Packaged Terminal Heat Pump (PTHP) and Unitary system should be modeled. The results of total energy, cooling energy, and heating energy consumption are estimated and compared. The influence of the variation of the coefficients of performance (COP) related to such systems is also investigated.

\section{The Case Study}

A house located in the city of Tripoli, Libya, was modeled using EnergyPlus-OpenStudio plugin. The house is a twofloor building as shown in Figure 3 with a total floor area of $280 \mathrm{~m}^{2}$ (net conditioned building area). The ground floor contains a kitchen, bathrooms, guest rooms and living area 
while the first floor is a sleeping floor that contains bedrooms contemporary house widely found in Libya. and bathrooms. This type of houses is considered as a

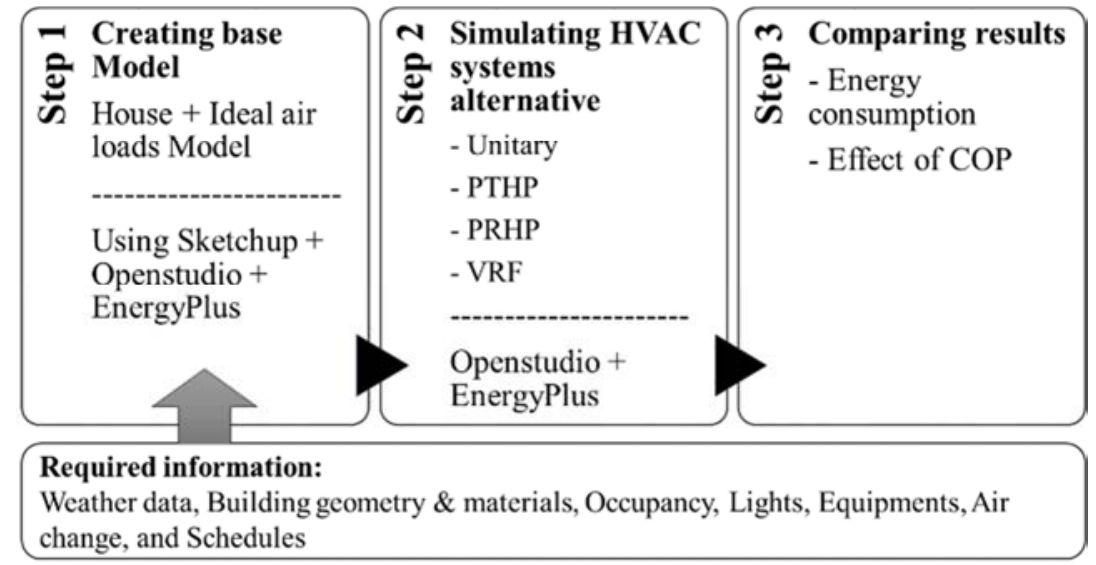

Figure 2. Methodology Flowchart.

The whole window to wall ratio (WWR) of the building is $15.64 \%$ distributed as $11.75 \%, 0.0 \%, 18.64 \%$, and $16.42 \%$ of North, East, South, and West faced walls, respectively. The eastern walls of the house are considered adiabatic walls as they are adjacent to neighbors' walls.

The values of the overall heat transfer coefficients of external walls, roof, windows and doors of this house are described in Table 1.

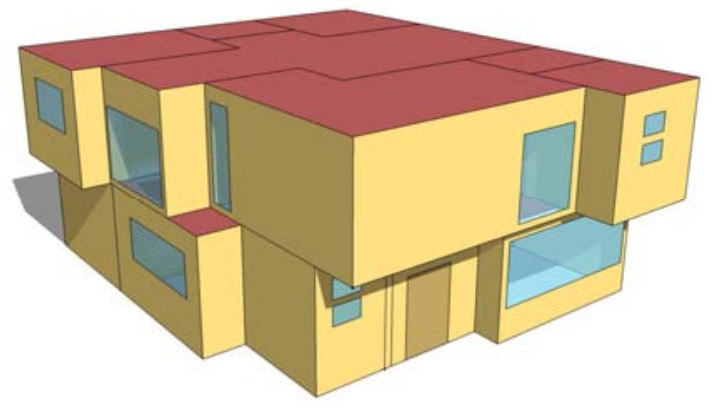

Figure 3. A three-dimensional SketchUp model of the building under study.

Table 1. Specifications of the building's envelope constructions.

\begin{tabular}{ll}
\hline Construction & Overall heat transfer coefficient, $\mathbf{W} / \mathbf{m}^{2} \mathbf{K}$ \\
\hline External Walls & 2.5 \\
Roof & 2.4 \\
Single glazed window & 5.8 \\
Doors & 1.8 \\
\hline
\end{tabular}

\section{HVAC Models and Simulation Parameters}

This section presents the main design parameters and the specifications of HVAC systems/models considered in this work. Table 2 contains the main assumptions related to the design parameters that were applied in the simulation of all HAVC models.

Some types of HVAC systems are available in EnergyPlus. These are selected for this study and they are described below. Settings and characteristics of those systems are listed within each related section. Cooling and heating supply air temperature set to be equal to $14^{\circ} \mathrm{C}$ and $40^{\circ} \mathrm{C}$, respectively, for all studied systems, while air ventilation was set to equal to zero for all considered systems.

Table 2. Simulation parameters

\begin{tabular}{ll}
\hline Parameter & Value \\
\hline Heating set point & $22^{\circ} \mathrm{C}$ \\
Cooling Setpoint & $24.5^{\circ} \mathrm{C}$ \\
Number of people & 0.02 people $/ \mathrm{m}^{2}$ \\
Heat gain from people & $120 \mathrm{~W} /$ person \\
Light definition & $11 \mathrm{~W} / \mathrm{m}^{2}$ \\
Equipment definition & $4 \mathrm{~W} / \mathrm{m}^{2}$ \\
Infiltration & $0.5 \mathrm{ACH}$ \\
\hline
\end{tabular}

\subsection{Ideal Air Loads Component}

Ideal air loads component is a practical component built in EnergyPlus that represents an ideal HVAC system. Energy consumption for ideal loads air systems is reported in the results as district heating and cooling, and does not appear as cooling and heating loads [20].

The component is assumed to supply cooling or heating air to the related zone to meet the zone load or up to specified limits that should be provided by the user. This is usually used when users have no interest in modeling the HVAC system and plant, or do not have a good knowledge of the types of HVAC systems. That allows achieving preliminary results without neither specifying some operating parameters nor specifying certain HVAC system.

\subsection{Unitary System}

A unitary system model is defined as a single unit that coordinates the operation of HVAC components. The model used here comprises of a fan, direct expansion heating coil, direct expansion cooling coil and electrical supplement heating coil. The fan can be operated in cycling or continuous supply modes. The specification of the system is 
listed as follows:

- Fan mode: Cycling

- Fan placement: Blow through

- Fan efficiency: $60 \%$

- Pressure rise: $300 \mathrm{~Pa}$

- Motor efficiency: $80 \%$

- Rated heating $\mathrm{COP}=5$

- Rated cooling COP = 3

- Electrical heating coil efficiency $100 \%$

\subsection{Packaged Terminal Heat Pump (PTHP)}

Packaged Terminal Heat Pumps are through-the-wall units. They represent an easy way to heat and cool small spaces. The specifications of the PTHP model used in this study are as follows:

- Fan efficiency $70 \%$

- Pressure rise $250 \mathrm{~Pa}$

- Motor efficiency $90 \%$

- Rated heating $\mathrm{COP}=5$

- Rated cooling $\mathrm{COP}=3$

\subsection{Packaged Rooftop Heat Pump (PRHP)}

The type of Packaged Rooftop Heat Pump used in this study comprises of a direct expansion heating coil, direct expansion cooling coil, electrical heating coil and constant flow fan. More details about the system are listed below:

- Electrical heating coil efficiency $90 \%$

- Constant volume fan

- Fan efficiency $=70 \%$

- Pressure rise $=500 \mathrm{~Pa}$

- Motor efficiency $=90 \%$

- Rated heating $\mathrm{COP}=5$

- Rated cooling COP $=3$

\subsection{Variable Refrigerant Flow System (VRF)}

VRF systems are considered light weighted and flexible. Each component can be transported and fitted easily. Several modules are used to cover high loads of cooling and heating capacities. VRF systems are known for their precise temperature control. Although Coefficients of the performance of VRF systems are practically superior to those for other systems, they have been assigned the same values that assumed previously for other systems. Some of the operating parameters for the system are listed here:

- VRF zone terminal

- Fan efficiency $60 \%$

- Pressure rise $=300 \mathrm{~Pa}$

- Motor efficiency $=80 \%$

- Rated heating $\mathrm{COP}=5$

- Rated cooling $\mathrm{COP}=3$

\section{Results and Discussion}

The results presented below focuses on the electricity consumption by the proposed HVAC systems/models. Those models are frequently applied in simulating buildings' annual energy consumption using EnergyPlus.

The total building energy consumption is shown in Figure 4 for the various HVAC models. It is in the range of 44009 $\mathrm{kWh}$ to $71213 \mathrm{kWh}$. PTHP and Unitary systems require low energy consumption of about $44000 \mathrm{kWh}$ while VRF and Packaged Rooftop Heat Pump require high energy consumption of $59725 \mathrm{kWh}$ and $54508 \mathrm{kWh}$, respectively.

The Ideal air loads component/model has recorded the maximum energy consumption of $71213 \mathrm{kWh}$, with an increase of about $61 \%$ compared to the Unitary system. This energy consumption value is high since the Ideal air loads model operates at $100 \%$ efficiency, i.e. its COP equal to 1 whereas the other models have COPs equal to 3 and 5 for cooling and heating, respectively. In this way, the Ideal Air load can be considered as a space energy needed to heat or cool the air but not the energy consumption of HVAC systems.

To look further into the details of the energy consumption of the HVAC systems, Figure 5 compares different categories of the energy consumption among the selected systems. It is evident from the figure that although Ideal Air Load has no equipment, it shows the maximum energy consumption for heating and cooling processes. Fans energy consumption is higher for central systems than the other units as expected. In general, the energy required for cooling is much greater than that needed for heating. For example, the share of cooling energy, heating energy and fans energy requirements of the total Unitary system energy requirement are $62 \%, 31 \%$, and $7 \%$, respectively.

Figure 6 presents the monthly HVAC energy consumption for the selected systems. The trend of the load is almost the same for all systems. The maximum energy consumption occurs in the month of July except for the VRF system where it takes place in the month of August. Minimum energy consumption due to the HVAC systems occur in the months of April and November with comparable values for the central systems and Ideal Air Loads component. That is because of the decrease of the HVAC performance due to low external thermal loads.

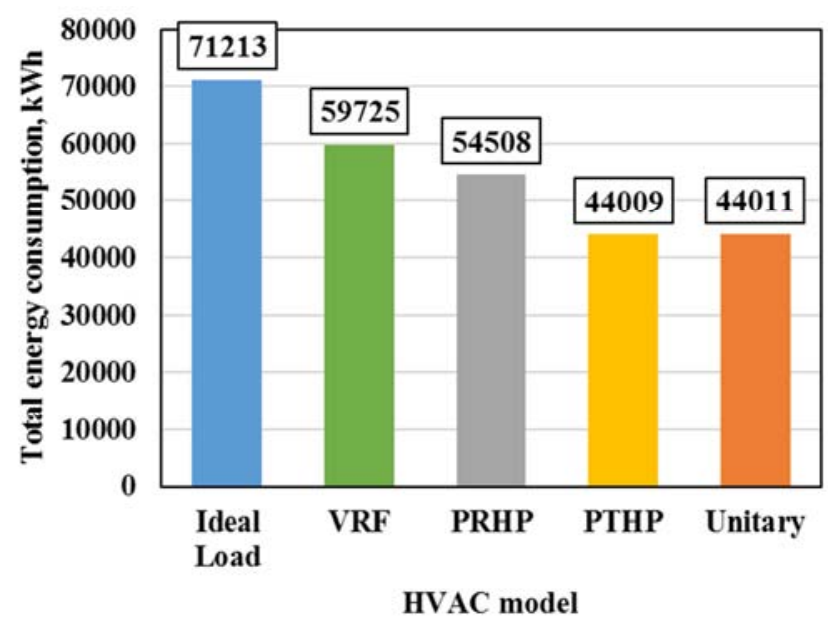

Figure 4. Building total energy consumption for different models. 


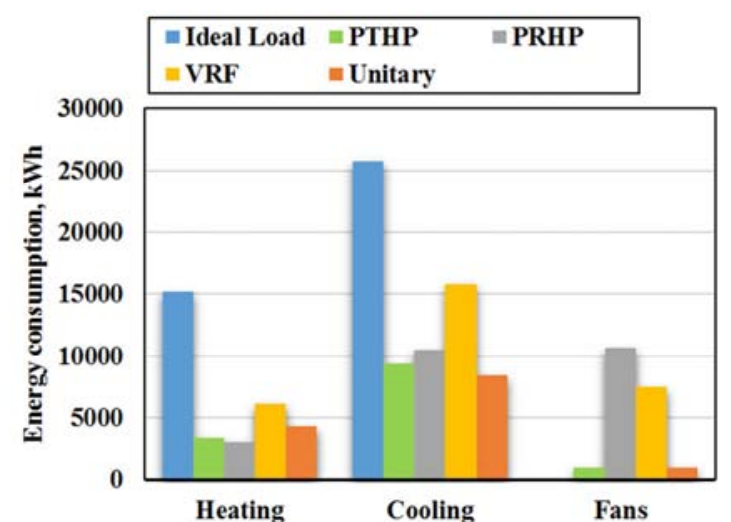

Figure 5. Cooling, heating, and fans energy consumption for various HVAC models.

Figure 7 represents a comparison between the energy consumption for the different models. In this case, all models have been assigned a unit value for the cooling and heating energy performance. The Ideal Air Loads provided the lowest energy consumption among the models. Energy consumption of Unitary and PTHP models are very close to that of the Ideal air loads whereas high energy consumption resulted in other systems.

Finally, the effect of changing cooling COP and heating COP on cooling and heating energy consumptions is studied for all models. As the Ideal Air Loads model is assumed to have $100 \%$ efficiency, it is represented in Figure 8 and Figure 9 by a single energy consumption point, diamond mark $(\diamond)$. In Figure 8 the relation between cooling energy consumption and cooling COP is presented. In this case, energy consumption obtained using Ideal Air Loads are less than other loads at COP equal to 1 . However, by increasing the COP of other models the values of energy consumption decrease drastically and the difference in energy consumption between different models becomes smaller. Figure 9 shows heating energy consumption versus heating COP. In this case, the trend of the change in energy consumption with COP for various models is similar to the previous case. However, energy consumption estimated assuming an Ideal Air Loads component is high for COP equal to 1 .

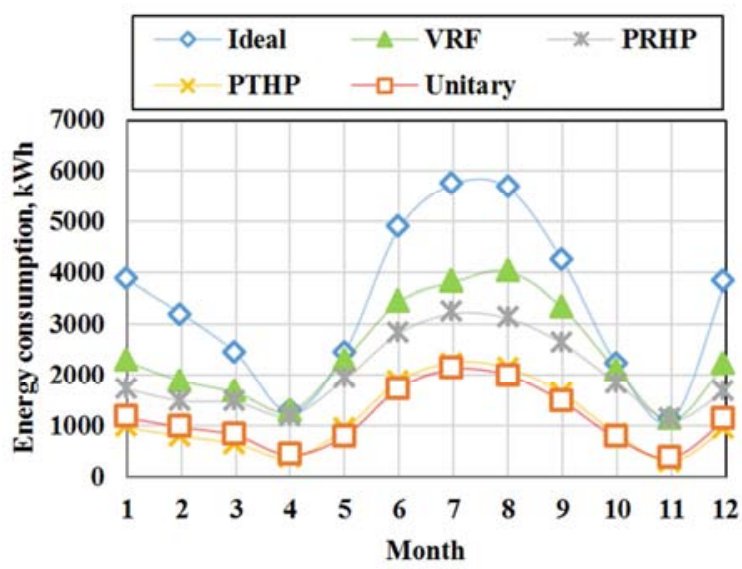

Figure 6. Monthly energy consumption for various models.

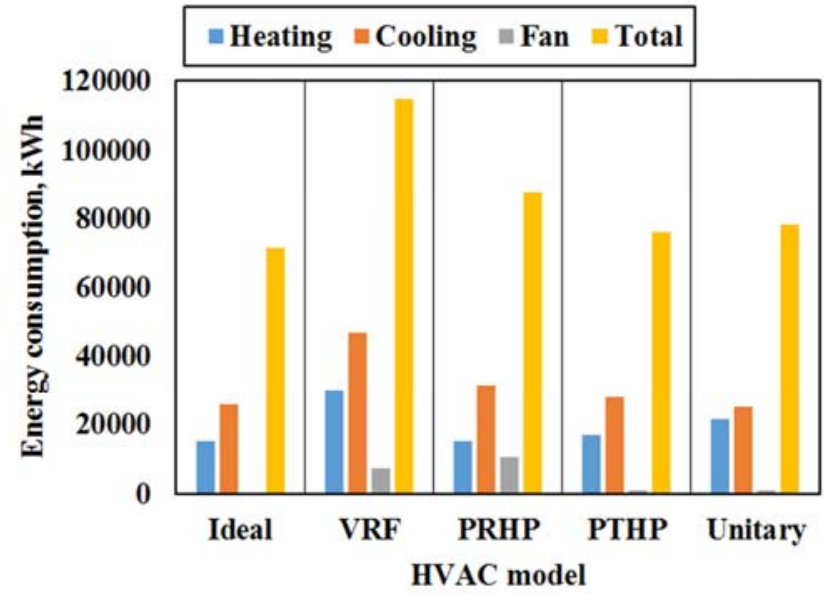

Figure 7. Annual energy consumption for heating COP and cooling COP equal to unity.

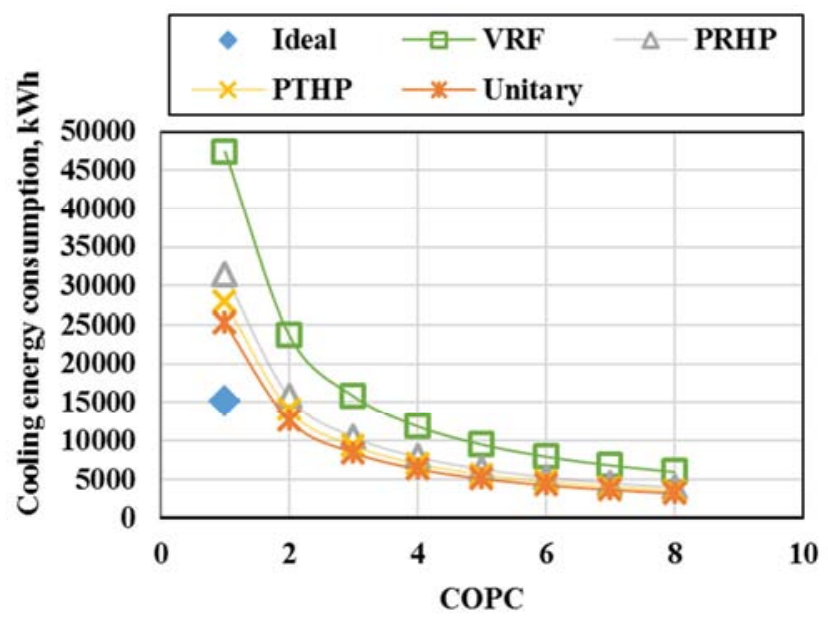

Figure 8. The effect of changing cooling coefficient of performance (COP) on cooling energy consumption.

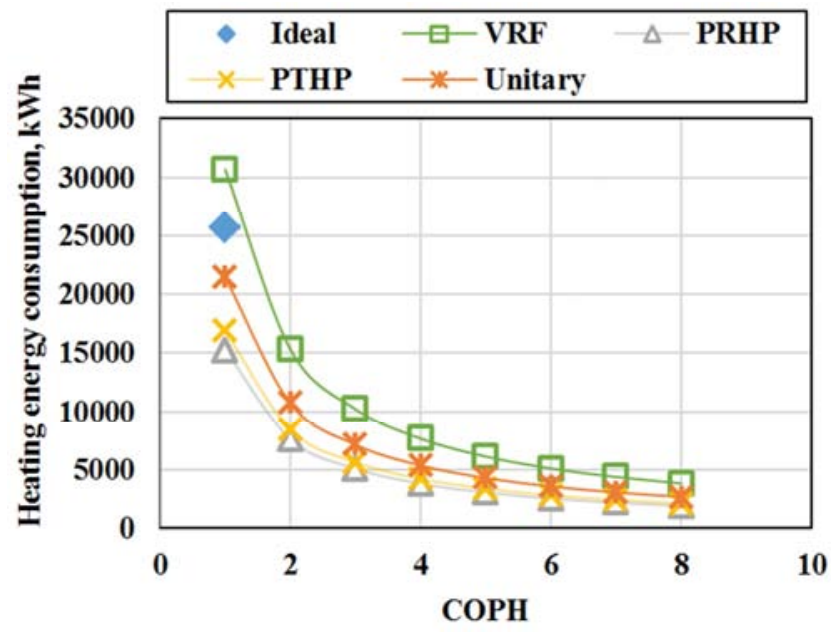

Figure 9. The effect of changing heating coefficient of performance (COP) on heating energy consumption.

\section{Conclusions}

HVAC systems consume a considerable amount of nationally produced energy. There is substantial research that 
focuses on improving the selection and operation of HVAC systems. This paper presents detailed study on the energy consumption of five HVAC models namely: Ideal Air Loads, Variable Flow Refrigerant, Packaged Rooftop Heat Pump, Packaged Terminal Heat Pump, and Unitary. These are frequently used by EnergyPlus users.

A medium size residential house in the city of Tripoli, Libya has been taken as a case study. It consists of two floors with $280 \mathrm{~m}^{2}$ area and has a total WWR of $16 \%$. Materials and constructions selected for the residential building model that is used in this study are the most commonly used materials in Libya today.

The results showed that (1) the virtual component "Ideal air Loads" used in EnergyPlus is very easy to implement. However, it is not an HVAC system, and the resulted energy consumption is very high as reasonable values of COP are not included. Therefore, its results can be misleading when the estimation of energy consumption is needed. (2) Although central air conditioning is becoming more popular in residential and commercial buildings due to aesthetic, comfort and ease of use issues, Unitary and PTHP systems consume minimum energy compared to other systems. (3) The difference between energy consumption of different HVAC systems decreases as the coefficient of performance increases for both heating and cooling use.

\section{Acknowledgements}

The author would like to thank Eng. Mohamed Ben-Naji and Professor Elhadi Dekam from the University of Tripoli, for their kind help in reviewing this work.

\section{References}

[1] Capehart BL, Kennedy WJ, Turner WC. Guide to Energy Management. Fifth Edit. The Fairmont Press, Inc; 2008.

[2] Pérez-Lombard L, Ortiz J, Pout C. A review on buildings energy consumption information. Energy and Buildings 2008; 40: 394-8. doi: 10.1016/j.enbuild.2007.03.007.

[3] Agha K and others. The potential contribution of solar energy in the household water heating: Technical and economic feasibility (in Arabic language). Tripoli: 2013.

[4] Afram A, Janabi-Sharifi F. Review of modeling methods for HVAC systems. Applied Thermal Engineering 2014; 67: 50719. doi: 10.1016/j.applthermaleng.2014.03.055

[5] Homod RZ. Review on the HVAC System Modeling Types and the Shortcomings of Their Application. Journal of Energy 2013; 2013: 10. doi: 10.1155/2013/768632.

[6] Trcka M, Hensen JLM. Overview of HVAC system simulation. Automation in Construction 2010; 19: 93-9. doi: 10.1016/j.autcon.2009.11.019.
[7] Jacobs P, Henderson H. State-of-the-Art Review: Whole Building, Building Envelope, and Hvac Component and System Simulation and Design Tools. Air-Conditioning and Refrigeration Technology Institute (ARTI); 2002.

[8] Little AD. Energy Consumption Characteristics of Commercial Building HVAC Systems. Volume II: Thermal Distribution, Auxiliary Equipment, and Ventilation. vol. 20. 1999. doi: DE-AC01-96CE23798.

[9] Vakiloroaya V, Samali B, Fakhar A, Pishghadam K. A review of different strategies for HVAC energy saving. Energy Conversion and Management 2014; 77: 738-54. doi: 10.1016/j.enconman.2013.10.023.

[10] Albayyaa H, Hagare D, Saha S. Comparative study of energy consumption for air conditioning between residential buildings with two different subflooring systems. ISEC Press, 2016.

[11] Zhou X, Hong T, Yan D. Comparison of HVAC system modeling in EnergyPlus, DeST and DOE-2.1E. Building Simulation 2014. doi: 10.1007/s12273-013-0150-7.

[12] Zhou X, Hong T, Yan D. Comparison of Building Energy Modeling Programs : HVAC Systems. 2013.

[13] Hasan A, Vuolle M, Sirén K. Minimisation of life cycle cost of a detached house using combined simulation and optimisation. Building and Environment 2008; 43: 2022-34. doi: 10.1016/j.buildenv.2007.12.003.

[14] DOE. EnergyPlus Energy Simulation Software. USA Department of Energy 2016. http://apps1.eere.energy.gov/ buildings/energyplus (accessed September 17, 2016).

[15] Shabunko V, Lim CM, Brahim S, Mathew S. Developing building benchmarking for Brunei Darussalam. Energy and Buildings 2014; 85: 79-85. doi: 10.1016/j.enbuild.2014.08.0 47.

[16] Shabunko V, Lim CM, Mathew S. EnergyPlus models for the benchmarking of residential buildings in Brunei Darussalam. Energy and Buildings 2016. doi: 10.1016/j.enbuild.2016.03.039.

[17] Alghoul SK, Alrijabo HG. The Effect of Alternative Double Glazed Windows on Buildings Energy Consumption. International Journal of Engineering Papers 2016; 1: 18-24.

[18] Fumo N, Mago P, Luck R. Methodology to estimate building energy consumption using EnergyPlus Benchmark Models. Energy and Buildings 2010; 42: 2331-7. doi: 10.1016/j.enbuild.2010.07.027.

[19] OpenStudio. OpenStudio User Documentation 2016; 2016. http://nrel.github.io/OpenStudio-user-documentation/.

[20] US Department of Energy. EnergyPlus ${ }^{\mathrm{TM}}$ Version 8.5 Documentation: Engineering Reference. 2016.

[21] Crawley DB, Lawrie LK, Winkelmann FC, Buhl WF, Huang YJ, Pedersen CO, et al. EnergyPlus: creating a new-generation building energy simulation program. Energy and Buildings 2001; 33: 319-31. doi: http://dx.doi.org/10.1016/S0378-7788 (00)00114-6. 